\title{
Identification and characterization of epitopes from influenza A virus hemagglutinin that induce broadly cross-reactive antibodies
}

\author{
YUAN LI ${ }^{1,2^{*}}$, HANYU HU $^{3 *}$, ZONGLI QI $^{1 *}$, JINGYING SUN $^{1,5}$, YAN LI $^{1}$, QING FENG ${ }^{1}$, CHUNYAN GUO $^{1}$, \\ HAIFANG WANG $^{1}$, PENGHUAZHAO ${ }^{1,5}$, YANG LIU ${ }^{1}$, XIANGRONG ZHAO ${ }^{1}$, \\ GUANGHUA WANG ${ }^{1,5}$, HAI ZHANG $^{4}$, LIBIN LIU ${ }^{2}$ and JUN HU ${ }^{1,5}$ \\ ${ }^{1}$ Central Experimental Laboratory, Shaanxi Provincial People's Hospital, \\ Key Laboratory of Infection and Immunity of Shaanxi Province, Xi'an, Shaanxi 710068; \\ ${ }^{2}$ Department of Pharmacy Medical College of Xi'an Peihua University, Xi'an, Shaanxi 710125; \\ ${ }^{3}$ School of Public Health, Sun Yat-sen University, Guangzhou, Guangdong 510080; \\ ${ }^{4}$ Center of Experimental Animals, The 4th Military Medical University, Xi'an, Shaanxi 710032; \\ ${ }^{5}$ Research Center of Cell Immunological Engineering of Shaanxi Province, Xi'an, Shaanxi 710068, P.R. China
}

Received April 20,2017; Accepted December 15, 2017

DOI: $10.3892 /$ ijmm.2017.3344

\begin{abstract}
Influenza is the most common infectious disease and is caused by influenza A virus (IAV) infection. Hemagglutinin (HA) is an important viral protein of influenza $\mathrm{A}$ and is a major component of current IAV vaccines. The side effects associated with IAV vaccination are well studied; however, the HA-induced immunopathological changes have remained largely elusive. The primary objective of the present study was to determine the tissue cross-reactive epitopes of HA proteins. Monoclonal antibodies (McAbs) were generated according to traditional methods using purified HA proteins from influenza vaccine lysates. The specificity of these McAbs was analyzed using western blot analysis and ELISA. Human tissue microarrays were employed for immunohistochemical staining to screen these McAbs. Rat brain tissues were subjected to immunohistochemical staining and electron microscopy to demonstrate the subcellular localization of antibodies targeting specific antigens. A total of 67 hybridoma cell lines positive for McAb against HA antigen were obtained. Three cross-reactive McAbs (H1-13, H1-15 and A1-10) were discovered through tissue screening.
\end{abstract}

Correspondence to: Dr Yuan Li or Dr Jun Hu, Central Experimental Laboratory, Shaanxi Provincial People's Hospital, Key Laboratory of Infection and Immunity of Shaanxi Province, Research Center of Cell Immunological Engineering of Shaanxi Province, 256 Youyi West Road, Xi'an, Shaanxi 710068, P.R. China E-mail: 1975312468@126.com

E-mail: hjj6562@163.com

*Contributed equally

Key words: influenza A virus, hemagglutinin, vaccine safety, monoclonal antibodies, cross-reactive epitope, porphyrin ring
Based on the 3 cross-reactive McAbs and the amino acid sequence of HA, the presence of two broadly cross-reactive HA epitopes, 194-WGIHH-198 and 365-WYGYHH-370, was assumed. McAbs against these synthetic epitope peptides were obtained. They reacted with porphyrin ring-containing molecules, including hemoglobin ( $\mathrm{Hb}$ ) and protoporphyrin, and with numerous types of normal tissue. In conclusion, the present study identified two broadly cross-reactive epitopes on HA (194-WGIHH-198 and 365-WYGYHH-370). Antibodies against these epitopes react with $\mathrm{Hb}$ and numerous types of important normal tissues/organs. These newly identified cross-reactive epitopes from IAV HA may provide crucial information for influenza research.

\section{Introduction}

Influenza, which is caused by influenza A virus (IAV) infection, is one of the most common infectious diseases in humans (1). The clinical symptoms of influenza vary according to the virulence of the IAV strain and the exposure history, age and immune status of the host. Seasonal influenza induces serious illness in 3-5 million people each year, with 2-500,000 deaths worldwide (2) and 30,000 deaths in the United States (3). In addition to annual epidemics, IAV is also the cause of infrequent pandemics, which may affect $>50 \%$ of the population in a single year and often leads to more severe disease than epidemic influenza. The 1918 pandemic was accountable for the death of an estimate of 50-100 million individuals (4,5). The 2009 H1N1 outbreak in Mexico and the United States quickly spread to numerous countries in the Americas, Europe and Asia, to become a new pandemic that seriously threatened global public health (6).

Vaccination is the most effective method to protect against IAV infection. Protection against influenza is primarily mediated by neutralizing antibodies against the major viral antigen hemagglutinin (HA) $(7,8)$. However, seasonal as well as pandemic influenza occur due to a lack of preformed immunity 
against HA, as it is susceptible to mutation. Epidemic strains with new epidemiological features will emerge along with the evolution of HA, which results in new viruses and a lagging immune protection (8).

The IAV vaccine provides protection to recipients depending on whether the vaccine matches circulating IAV strains. A mismatched IAV vaccine will fail to induce protective immune responses. However, outside their protective or non-protective effects, current IAV vaccines have side effects, which may include shock, renal function damage and the neurologic disorder Guillain-Barre syndrome (GBS) (9). The symptoms associated with IAV infection and the side effects of IAV vaccination have been issues for scientists, the vaccine industry and governments year after year. The mechanisms of influenza vaccination-associated GBS and numerous other serious side effects remain to be fully elucidated and continue to pose risks. For instance, numerous efforts have been made to determine the association between GBS and anti-ganglioside antibodies (anti-GM-1), while the involved mechanisms have remained elusive (10-16). The 1976 swine flu vaccines were known for resulted in a higher incidence of GBS compared with unvaccinated people $(17,18)$. Preserved samples of monovalent and bivalent 1976 vaccines were demonstrated to induce anti-GM-1 antibodies in mice, as did vaccines from 1991-1992 and 2004-2005 (10). These studies ruled out the initial suspicion that the vaccines were contaminated by moieties including Campylobacter jejuni antigens, which mimic human gangliosides to elicit an anti-GM-1 antibody response in susceptible recipients (10); however, questions remain regarding the other vaccine components.

Cross-protective vaccines (19-22), antibodies (23-26) and $\mathrm{T}$ cells (27-30) against IAV infections have been well studied and reported. However, the cross-reactive immune response associated with the pathology of influenza has remained to be elucidated. By preparing monoclonal antibodies (McAbs) against HA, the present study successfully obtained a series of McAbs with a spectrum of cross-reactivities. In addition, two antigenic epitopes on HA were identified that may induce antibodies with a wide range of cross-reactivity, including that in nervous tissues, hemoglobin $(\mathrm{Hb})$ and numerous other crucial types of organs and tissues. This implies that the symptoms of IAV infection and the side effects of IAV vaccination may result from immunopathological reactions induced by their HA cross-reactive epitopes.

\section{Materials and methods}

Ethical approval. This study was also performed in strict accordance with the recommendations in the Guide for the Care and Use of Laboratory Animals of the National Institutes of Health. The protocol was approved by the Committee on the Ethics of Animal Experiments of Shaanxi Provincial People's Hospital (Xi'an, China; permit no. 01-0420). All surgeries on animals were performed under sodium pentobarbital anesthesia and every effort was made to minimize suffering.

\section{McAb preparation}

Immunogens. HA protein vaccine purified from 2009 H1N1 lysate is a State Food and Drug Administration-approved influenza vaccine (cat. no. S20090015; Hualan Vaccine Ltd.,
Xinxiang, China). The seasonal influenza A1, A3 and B vaccines were obtained from Dalian Yalifeng Biotechnology, Ltd. (Dalian, China). The 2009 H1N1 HA epitope polypeptides were synthesized by Meilian Biotechnology, Ltd. (Xi'an, China). Carboxy-terminal polyglutamic acid was added to facilitate coating onto the ELISA plate and two amino acids after each epitope were included to reduce the effect of negative charges of polyglutamic acid. The following epitopes were used: P11, WGIHH-PS-EEEE corresponding to the 2009 H1N1 HA amino acids 194-198; P14, WYGYHH-QN-EEEE corresponding to the 2009 H1N1 HA amino acids 365-370; P11F, FGIHH-PS-EEEE, modified P11 by substitution of phenylalanine with tryptophan to disrupt epitope P11; P14R, WYGYRH-QN-EEEE, modified P14 by substitution of the first histidine with arginine to disrupt epitope P14.

Antibodies. Five McAbs (H1-13, A1-6, H1-15, A1-10 and H1-17) against the HA protein of H1N1 influenza virus were previously prepared in our laboratory (31).

$B A L B / c$ mice. A total of 40 female BALB/c mice (age, 8 weeks; weight, $18 \pm 20 \mathrm{~g}$ ) were obtained from the Laboratory Animal Center of the Fourth Military Medical University (Xi'an, China) and maintained at $23^{\circ} \mathrm{C}$, with a humidity of $40-70 \%$ in a $12 \mathrm{~h}$ light/dark cycle. Mice were provided with free access to water and food.

Immunization protocol. For the H1N1 vaccine, priming was performed by subcutaneous injection of $2 \mu \mathrm{g}$ vaccine in $0.1 \mathrm{ml}$ phosphate-buffered saline (PBS). Boosting was performed four weeks later by intraperitoneal injection of $2 \mu \mathrm{g}$ vaccine in $0.1 \mathrm{ml}$ PBS and an intraperitoneal immunization with $2 \mu \mathrm{g}$ vaccine in $0.1 \mathrm{ml}$ PBS vaccine was performed three days prior to fusion ( 6 weeks following first boost). For epitope polypeptides, $2 \mu \mathrm{g}$ polypeptide was applied onto a nitrocellulose membrane, followed by air drying in the hood and inguinal subcutaneous embedding for priming. After four weeks, boosting was performed twice with $2 \mu \mathrm{g} / 0.1 \mathrm{ml}$ peptide through intraperitoneal immunizations with a biweekly interval. A pulse immunization was performed by intraperitoneal injection of $2 \mu \mathrm{g} / 0.1 \mathrm{ml}$ peptide three days prior to fusion.

$M c A b$ preparation. The feeder layer cells, immune spleen cells and myeloma $\mathrm{Sp} 2 / 0$ cells were routinely prepared, and the hybridoma were prepared using polyethylene glycol-mediated chemical fusion (31).

Biological characterization of the McAbs. A McAb subtype identification kit from Southern Biotech (Birmingham, AL, USA; cat. no. 5300-05) was used to identify the antibody class and subclass according to the manufacturer's instructions. The titration of the antibodies was performed as follows: Serial dilutions of the McAb containing ascetic fluid were prepared and the antibody reactivity was detected with the indirect ELISA established in-house (32). The McAb titer was considered to be the highest dilution determined to display binding with the cut-off value of antibody optical density at $450 \mathrm{~nm}\left(\mathrm{OD}_{450}\right) /$ control $\mathrm{OD}_{450} \geq 2.1$ (33). Similar to the indirect ELISA with HA antigen, the specificities of the McAbs were determined with HA-coated plates (National Vaccine 
and Serum Institute, Beijing, China) and cross-reactivity was evaluated with heme-protoporphyrin, chlorophyll and vitamin B12 and Hg-coated plates (Sigma-Aldrich; Merck KGaA, Darmstadt, Germany). The coating concentration for the above antigens was $2.5 \mu \mathrm{g} /$ well.

Western blot analysis. The specificity of the McAbs was analyzed using western blot developed with diaminobenzidine (DAB) substrate. A total of $20 \mu \mathrm{g}$ of each HA sample (1.392 mg/ml obtained from $\mathrm{H} 1 \mathrm{~N} 1$ vaccine lysate) and each human leukocyte antigen (HLA)-B27E and each HLA-B27E protein with a His tag was mixed with an SDS electrophoresis sample buffer, resolved by $12 \%$ sodium dodecyl sulfate-polyacrylamide gel electrophoresis (SDS-PAGE) and transferred onto a nitrocellulose membrane (GE Healthcare Life Sciences, Little Chalfont, UK). After blocking with 5\% skimmed milk for $30 \mathrm{~min}$ at room temperature, the membranes were treated with $\mathrm{H} 1 \mathrm{~N} 1 \mathrm{McAb}$ supernatants of the cultivated hybridoma at $37^{\circ} \mathrm{C}$ for $1 \mathrm{~h}$. Membranes were probed with horseradish peroxidase (HRP)-linked anti-mouse polyclonal secondary antibody (cat. no. CW102s; 1:2,000) at $37^{\circ} \mathrm{C}$ for $1 \mathrm{~h}$, and bands were visualized via chemiluminescence with a DAB substrate (both from CW Biotech, Beijing, China).

Immunohistochemical staining of the tissue microarray (TMA). A normal human TMA was purchased from Shaanxi Chaoying Biotech, Ltd. (Xi'an, China; parent company: Cybrdi, Frederick, MD, USA), which included 33 human tissue specimens in duplicates for a total of 66 specimens. The slide was previously treated with aminopropyltriethoxysilane. Immunohistochemical staining was performed as previously described (34). In brief, paraffin sections of tissues were deparaffinized, hydrated, endogenous peroxidase was blocked with $3 \% \mathrm{H}_{2} \mathrm{O}_{2}$ at room temperature for $20 \mathrm{~min}$, followed by blocking of unspecific binding with buffer containing goat serum (cat. no. CW2134; CW Biotech) for $30 \mathrm{~min}$. The samples were stained with primary antibody (McAb supernatants of cultured hybridoma against HA) at $4^{\circ} \mathrm{C}$ overnight, stored at room temperature for $60 \mathrm{~min}$, washed 3 times with PBS, and incubated with 1:500 HRP-labeled sheep anti-mouse secondary antibody (cat. no. CW0102S; CW Biotech) at $37^{\circ} \mathrm{C}$ for $40 \mathrm{~min}$. After 3 washes with PBS, DAB and hematoxylin at room temperature for $3 \mathrm{~min}$ were added for color development and color enhancement, respectively, according to the manufacturer's instructions.

Immunogold electron microscopic analysis of normal rat brain tissue. Pre-embedding immunogold-silver cytochemistry was performed as previously described (35). In brief, 2 healthy female Sprague Dawley rats (180-220 g) were purchased from the laboratory animal center of Fourth Military Medical University and kept under specific pathogen conditions at $23^{\circ} \mathrm{C}$ with a humidity of $40-70 \%$ and a $12 \mathrm{~h}$ light/dark cycle. Rats were provided with free access to food and water. Rats were intraperitoneally anesthetized with $100 \mathrm{mg} / \mathrm{kg}$ sodium pentobarbital and perfused with $4 \%$ paraformaldehyde. The skull was rapidly opened, and the cerebral cortex tissue was taken and immersed in $3 \%$ glutaraldehyde fixative solution for $3 \mathrm{~h}$. The snap-frozen tissue was sectioned into 60-70 $\mu \mathrm{m}$ slices using a vibratome (VT1000S; Leica Microsystems, Wetzlar,
Germany). The slices were transferred to PBS containing 25\% sucrose and $10 \%$ glycerol and were soaked for $1 \mathrm{~h}$. After a repeated freezing and thawing process, the tissue slices were placed in a blocking solution containing 5\% bovine serum albumin (Takara Biotechnology Co., Ltd., Dalian, China) at $37^{\circ} \mathrm{C}$ for $4 \mathrm{~h}$. The primary antibody (A1-10 or H1-13; 1:100) was added, and the tissue slices were incubated overnight at $4^{\circ} \mathrm{C}$; after washing the tissue slices with PBS, the secondary antibody biotinylated goat anti-mouse immunoglobulin (Ig) G containing gold particles (cat. no. 2002-06D232; 1:200; Dako; Agilent Technologies, Inc., Santa Clara, CA, USA) was added, and the slices were incubated overnight at $4^{\circ} \mathrm{C}$. After washing, the sections were fixed with PBS fixation buffer containing $0.5 \%$ osmium tetroxide for $1 \mathrm{~h}$ and dehydration was performed with a gradient series of ethanol. After being immersed in propylene oxide, the slices were embedded in Epon-812 resin. After $50 \mathrm{~nm}$ ultrathin sectioning, the slices were counterstained with uranyl acetate and lead citrate. The sections were observed under a transmission electron microscope (JEOL Ltd., Tokyo, Japan).

Immunoblocking ELISA. After identifying the three cross-reactive McAbs A1-10, H1-13 and H1-15, their specificity was further determined with an in-house immunoblocking ELISA. The 96-well plates were coated with H1N1 influenza vaccine $(2.5 \mu \mathrm{g} / \mathrm{ml})$. After washing three times with Tris-buffered saline (TBS), antibodies diluted at 1:100 and pre-reacted with $(200 \mu \mathrm{g} / \mathrm{ml})$ heme, $\mathrm{Hg}$, polypeptide P11 or polypeptide $\mathrm{P} 14$ for $1 \mathrm{~h}$ at $37^{\circ} \mathrm{C}$ were added $(100 \mu \mathrm{l} /$ well $)$, followed by incubation for $1 \mathrm{~h}$ at $37^{\circ} \mathrm{C}$. After washing three times with TBS, HRP-labeled sheep anti-mouse secondary antibody (100 $\mu \mathrm{l} /$ well; cat. no. CW0102S; 1:1,000; CW Biotech) was added, and then the plates were incubated for $1 \mathrm{~h}$ at $37^{\circ} \mathrm{C}$. After another three washes, $\mathrm{O}$-phenylenediamine dihydrochloride $(0.4 \mathrm{mg} / \mathrm{ml})$ in $50 \mathrm{mM}$ sodium citrate $(\mathrm{pH} 5.5)$ containing $0.03 \% \mathrm{H}_{2} \mathrm{O}_{2}$ was added to each well, followed by incubation at $37^{\circ} \mathrm{C}$ for $30 \mathrm{~min}$. A $0.9 \mathrm{M} \mathrm{H}_{2} \mathrm{SO}_{4}$ solution was added to terminate the reaction; the $\mathrm{OD}_{450} \mathrm{~nm}$ was then detected using an ELISA reader.

The relative inhibitor index (RI) was calculated as follows: $\mathrm{RI}=\left(\mathrm{OD}_{450} \mathrm{McAb}-\mathrm{OD}_{450}\right.$ antigen pre-reacted $\left.\mathrm{McAb}\right) / \mathrm{OD}_{450}$ $\mathrm{McAb}$. RI $\leq 0.4$ indicates that the antibody does not react with the blocking antigen; RI 0.4-0.8 indicates that the antibody is reactive with the blocking antigen; $\mathrm{RI} \geq 0.8$ indicates that the antibody consistently reacted with the blocking antigen.

Statistical analysis. All values are expressed as the mean \pm standard deviation. The SPSS 10.0 statistical package (SPSS Inc., Chicago, IL, USA) was used for all statistical analyses. Comparisons of group means were performed by analysis of variance with Newman-Keuls post hoc test. $\mathrm{P}<0.05$ was considered to indicate a statistically significant difference.

\section{Results}

McAbs produced by immunization of mice withIAVHA antigen. Sixty-seven hybridoma cell lines reactive to $\mathrm{McAb}$ against IAV HA antigen were obtained from 3 experiments; among these, 47 produced IgG class and 20 produced IgM class antibodies; 25 were H1 subtype-specific, and the remaining ones 
Table I. Characterization of the cross-reactivity of McAbs.

\begin{tabular}{lcccccccc}
\hline McAb & Ig subtype & Ascitic fluid & HA & Hg & Heme & PP & Cp & VitB12 \\
\hline H1-13 & IgG & $10^{-2}$ & $14.10 \pm 0.26$ & $2.90 \pm 0.26^{\mathrm{a}}$ & $9.43 \pm 1.03^{\mathrm{a}}$ & $2.53 \pm 0.06^{\mathrm{a}}$ & $2.17 \pm 0.06^{\mathrm{a}}$ & $1.93 \pm 0.15^{\mathrm{a}}$ \\
$\mathrm{H} 1-15$ & IgM & $10^{-2}$ & $3.00 \pm 0.26^{\mathrm{b}}$ & $6.80 \pm 0.35^{\mathrm{b}}$ & $9.27 \pm 0.31^{\mathrm{b}}$ & $3.47 \pm 0.64$ & $2.23 \pm 0.23^{\mathrm{b}}$ & $2.90 \pm 0.10^{\mathrm{b}}$ \\
$\mathrm{A} 1-10$ & IgM & $10^{-3}$ & $14.33 \pm 0.78$ & $4.97 \pm 0.51^{\mathrm{b}}$ & $12.20 \pm 0.10^{\mathrm{b}}$ & $2.43 \pm 0.15^{\mathrm{b}}$ & $3.77 \pm 0.06^{\mathrm{b}}$ & $2.43 \pm 0.58^{\mathrm{b}}$ \\
$\mathrm{A} 1-6$ & IgG & $10^{-7}$ & $12.23 \pm 1.36$ & $1.17 \pm 0.21$ & $1.13 \pm 0.15$ & $1.43 \pm 0.21$ & $1.07 \pm 0.23$ & $0.93 \pm 0.15$ \\
H-17 & IgM & $10^{-6}$ & $13.37 \pm 1.21$ & $1.00 \pm 0.10$ & $1.03 \pm 0.06$ & $1.13 \pm 0.06$ & $1.07 \pm 0.12$ & $1.50 \pm 0.17$ \\
\hline
\end{tabular}

The antibody titer in the ascetic fluid was evaluated by indirect ELISA with an influenza virus A HA-coated plate. The reactivity of each McAb against the listed antigens was evaluated by ELISA. Results are expressed as the ratio of the optical density at $450 \mathrm{~nm}$ of the same antigen to the respective $\mathrm{McAb}$ vs. the $\mathrm{Sp} 20$ negative control $(\mathrm{McAb} / \mathrm{Sp} 20$ or $\mathrm{P} / \mathrm{N})$. $\mathrm{P} / \mathrm{N} \geq 2.1$ was the cutoff value for a reaction to be considered positive. ${ }^{\mathrm{a}} \mathrm{P}<0.05$, ratio of H1-13 McAb vs. ratio of A1-6 McAb; ${ }^{\mathrm{b}} \mathrm{P}<0.05$, ratios of A1-10 and H1-15 McAbs vs. ratio of H1-17 McAb. HA, hemagglutinin; Hg, hemoglobin; PP, protoporphyrin; Cp, chlorophyll; VitB12, vitamin B12; Ig, immunoglobulin; McAb, monoclonal antibody; $\mathrm{P}$, positive; $\mathrm{N}$, negative.

cross-reacted with the other HA subtypes, including 3 (H1-13, H1-15 and A1-10) that reacted not only with IAV HA but also with a wide variety of antigens as previously reported $(31,32)$. The present study focused on these 3 cross-reactive McAbs.

Characteristics of the cross-reactive McAbs. The titers of the McAbs against IAV HA vary in a considerable range (as measured by indirect ELISA) from $10^{-2}$ to $10^{-7}$ (Table I). While a limited number of experiments was performed in the present study, McAbs with a higher titer usually have a higher specificity and that McAbs with a lower titer usually have a lower specificity; however, this is not a universal rule. A group of 3 lower-titer McAbs (H1-13, H1-15 and A1-10) reacted not only with IAV HA but also with recombinant proteins with His-tag that were not associated with HA (Table I and Fig. 1). Two IVA H1 subtype-specific McAbs (A1-6 and H1-17) were included in this study as controls. The western blot analysis included the following recombinant proteins with a His-tag: HLA-B27E. The recombinant proteins without His-tag testing included HLA-B27E. The 3 McAbs with the lower ELISA titers reacted with proteins with a His-tag but not with the recombinant proteins without a His-tag, with the exception of IAV HA. Fig. 1 displays the results of only HLA-B27E with and without His-tag as the representation.

The imidazole ring is an important structural feature of histidine and a the His-tag is composed of a chain of histidines, rendering it structurally similar to the porphyrin ring containing four imidazole moieties. Along this line of reasoning, the cross-reactive McAbs were assessed using indirect ELISA with porphyrin ring-containing molecules (including $\mathrm{Hg}$, protoporphyrin, chlorophyll and vitamin B12) in parallel with IAV HA-coated microwell plates with positive results from all. This experiment expanded the knowledge on the cross-reactivity of the McAbs from the His-tag to a spectrum of important biomolecules (Table I).

Reactivity of the anti-HA McAbs to human normal tissues. To accurately determine the reactivity of the cross-reactive anti-HA McAbs with normal human tissues, they were tested using a normal human TMA. The results are summarized in Table II. Fig. 2 displays the reactivity to normal human brain tissue as an example. All three cross-reactive anti-HA

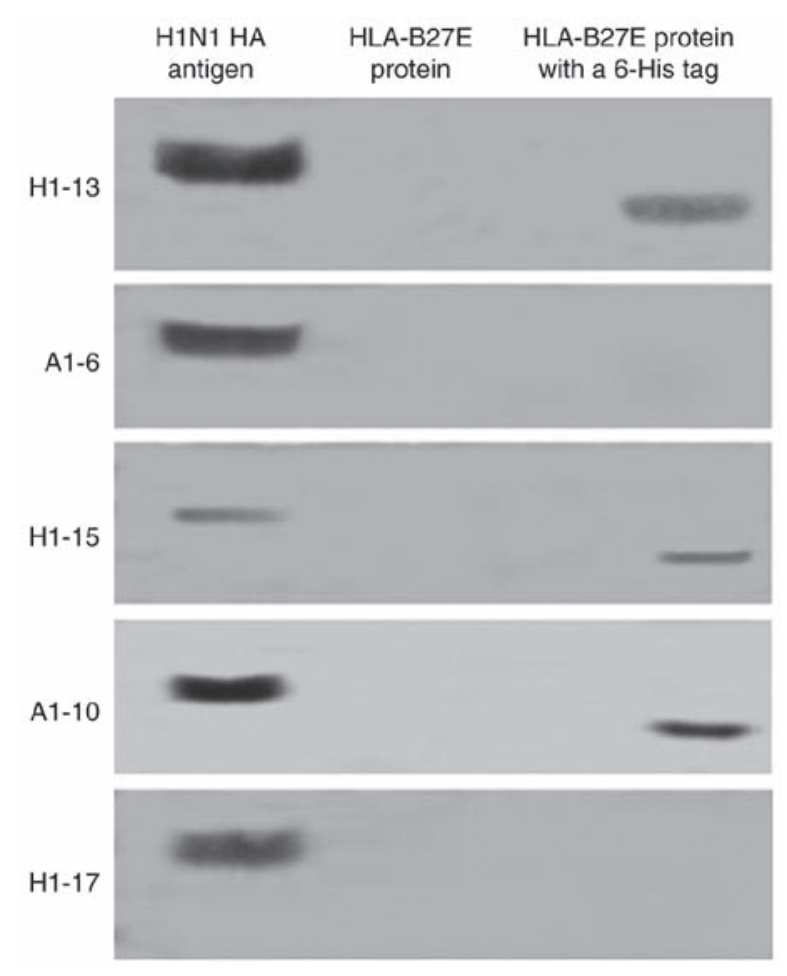

Figure 1. Reactivity of the anti-HA McAbs assessed by western blot analysis. McAbs: H1-13, A1-6, H1-15, A1-10, H1-17. Antigens: H1N1 HA, HLA-B27E protein, HLA-B27E protein with a 6-His tag. McAbs, monoclonal antibodies; HA, hemagglutinin; HLA, human leukocyte antigen.

McAbs consistently reacted with red blood cells, neuronal cells and certain neurogliocytes. No significant binding was observed with the other organs assessed. The HA-specific McAbs A1-6 (IgG) and H1-17 (IgM) were used as an isotype control; they were not reactive to the TMA.

Anti-HA McAb binds to normal rat brain tissue. In the immune colloidal gold-silver electron microscopy study, normal rat brain tissue was stained with the cross-reactive McAb A1-10. The results indicated that the antibody specifically binds to neuronal cells of rat brain cortex tissue (Fig. 3). The binding sites were identified to be located in the neuronal cell cytoplasm (Fig. 3A) and dendrites (Fig. 3B). However, there was no indication of 


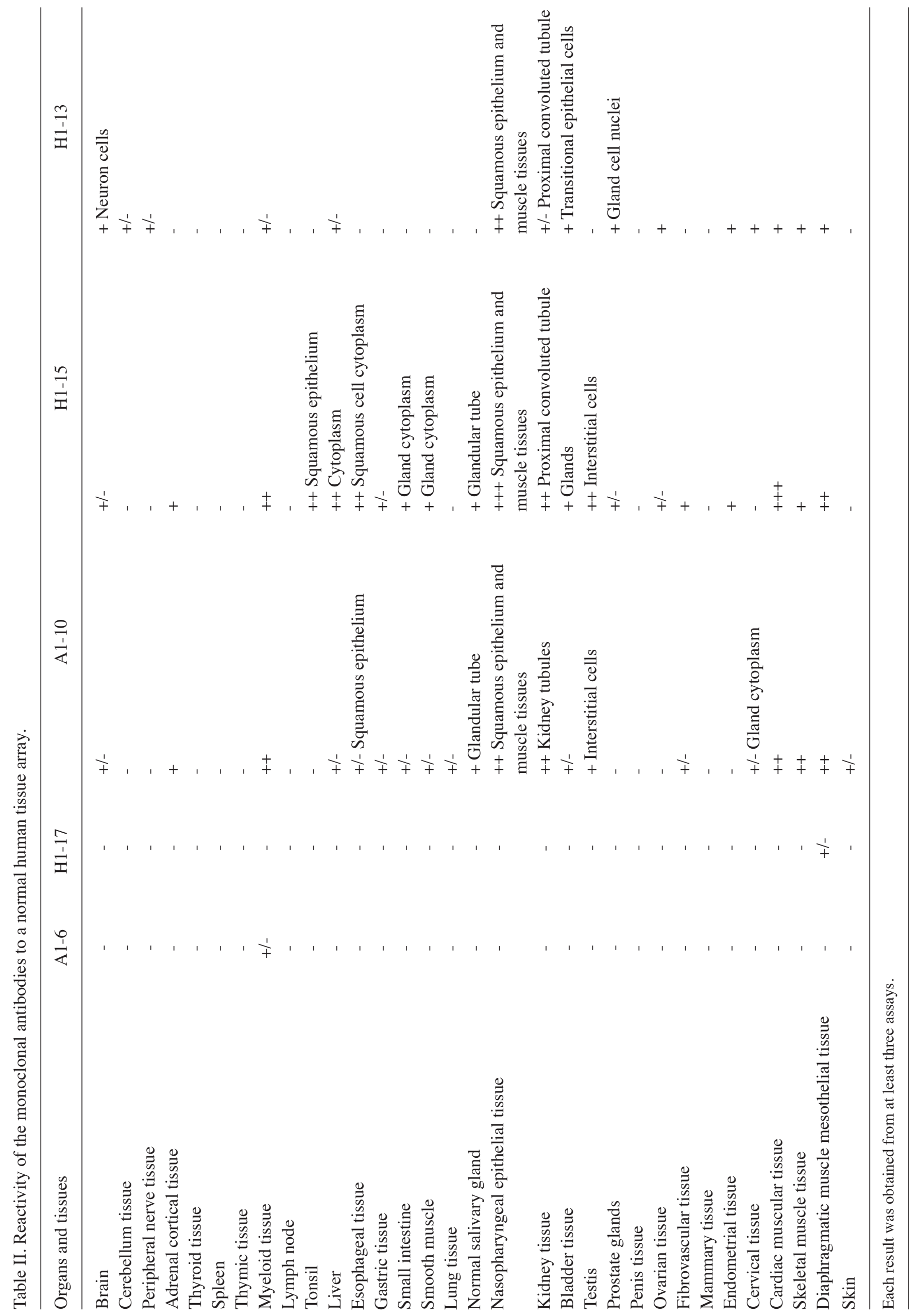




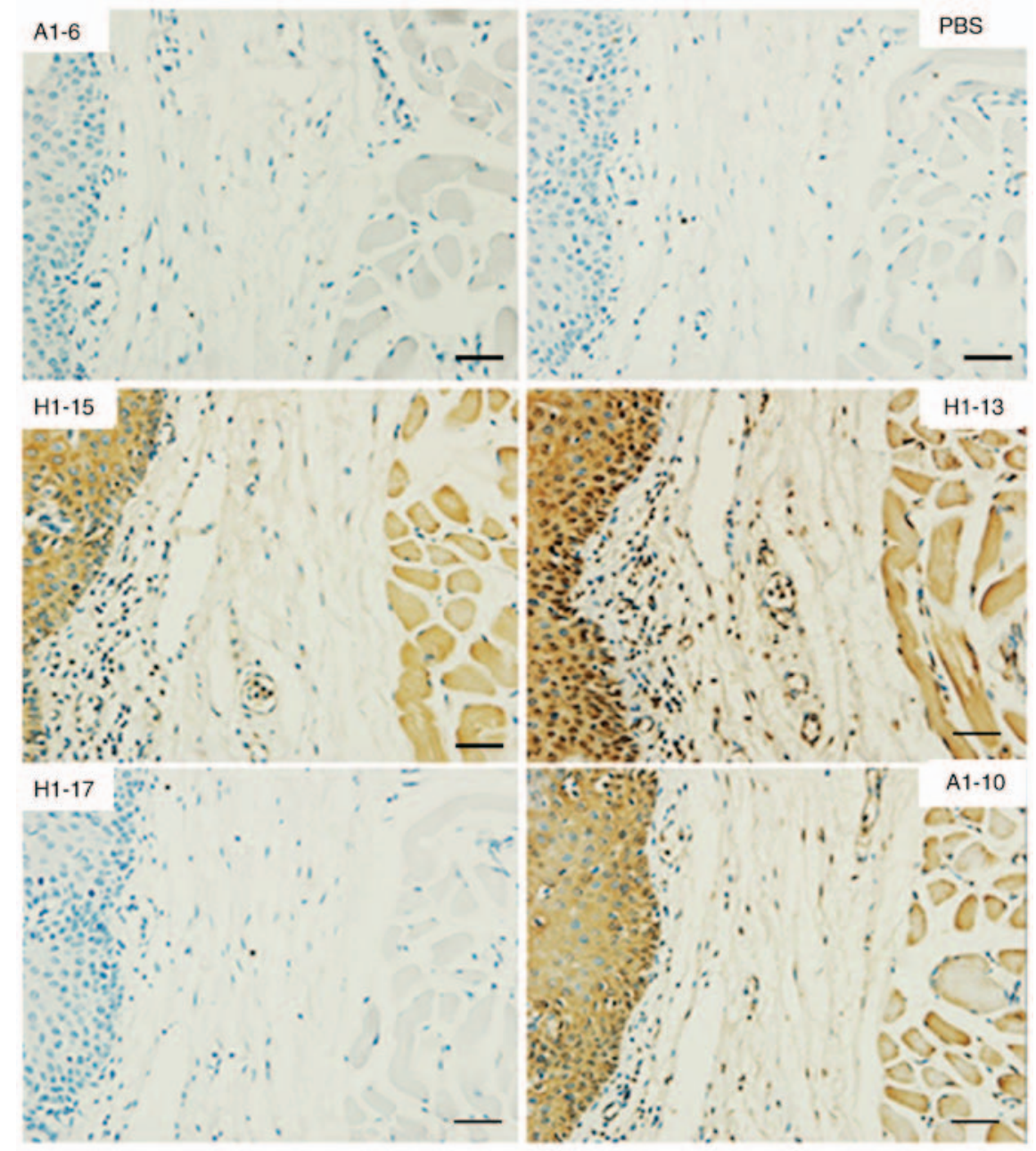

Figure 2. Cross-reactivity of the anti-HA McAbs in an immunohistochemistry experiment on normal human brain tissues. The slides were stained with anti-HA McAbs (A) A1-6 (no cross-reactivity, as negative IgG1 isotype control); (B) PBS (negative control); (C) H1-15 (cross-reactive, IgM); (D) H1-13 (cross-reactive, IgG1); (E) H1-17 (no cross-reactivity, negative IgM control); (F) A1-10 (cross-reactive, IgM). Scale bar, $40 \mu \mathrm{m}$. Ig, immunoglobulin; McAbs, monoclonal antibodies; HA, hemagglutinin.

binding to any specific organelles, and there was no specific reaction with the neuronal nucleus or surrounding cells.

Prediction and characterization of the cross-reactive epitopes on IAV HA. Two imidazole-rich clusters were identified by visually scanning the HA amino acid sequence (Fig. 4B). They are the P11 (194-WGIHH-198) and P14 (365-WYGHH-370) epitopes (Fig. 4C). To prove the importance of the imidazole ring cluster for these two cross-reactive epitopes, peptide P11F (FGIHH) were designed by substituting one imidazole-containing amino acid (tryptophan) with another aromatic amino acid (phenylalanine). In the same manner, peptide P14R (WYGYRH) was designed by substituting the first histidine with another basic amino acid (arginine).

To confirm the selected HA cross-reactive epitopes, two McAbs were prepared from hybridoma made by the fusion of $\mathrm{Sp} 2 / 0$ cells with spleen cells of mice immunized with polypeptide P11 and P14, respectively. These are P11-A1 and P11-A2, as well as P14-A1 and P14-A2; all of which are IgM class. All reacted with the two native epitopes but not with the modified peptides P11F or P14R in the indirect ELISA. This indicated that a minimum number of imidazole rings is required and that there were cross-reactions between the two epitopes.
Of note, all of the epitopes reacted with HA and heme more efficiently than with their own peptides (Table III). This also indicates that the number of imidazole rings in the antigen made a difference; the more imidazol rings in the molecule, the stronger its reaction. In addition, the McAb Hb-A18 generated by immunizing mice with $\mathrm{Hb}$ reacted with heme and the unassociated HA in the indirect ELISA; this further suggests the possibility of sharing an epitope between the imidazole ring-rich molecules including $\mathrm{Hg}$ and $\mathrm{HA}$ (Table III). The HA-specific McAb H1-17 was included in the ELISA as a negative control and system control.

Further confirmation of the broad cross-reactive epitopes of HA. P11 and P14 are liner epitopes. In the above experiments, they reacted with HA and other antigens coated on the plate or attached to the NC membrane after SDS-PAGE, which means that those antigens may already be denatured. To confirm these epitopes, they were first reacted with a series of soluble native antigens to block the McAbs from binding to HA coated on the microwell plate of the indirect ELISA in parallel with the McAbs without pre-reaction. As presented in Fig. 5, protoporphyrin, heme, P11 and P14 efficiently blocked all 3 cross-reactive McAbs from binding to HA on 
Table III. Epitope specificity of the McAbs.

Detection antigens

\begin{tabular}{lccccccc}
\cline { 3 - 7 } McAbs & Immunization antigens & HA & Heme & Peptide P11 & Peptide P14 & Peptide P11F & Peptide P14R \\
\hline P11-A1 & 11P & $4.03 \pm 0.67$ & $6.93 \pm 0.06$ & $2.73 \pm 0.65$ & $2.97 \pm 0.25$ & $1.17 \pm 0.21^{\mathrm{b}}$ & $1.20 \pm 0.10^{\mathrm{c}}$ \\
P11-A2 & $11 \mathrm{P}$ & $5.00 \pm 0.98$ & $4.50 \pm 0.44$ & $3.36 \pm 0.32$ & $2.50 \pm 0.35$ & $1.23 \pm 0.06^{\mathrm{b}}$ & $1.00 \pm 0.27^{\mathrm{c}}$ \\
P14-A1 & $14 \mathrm{P}$ & $4.70 \pm 0.62$ & $6.83 \pm 0.51$ & $3.43 \pm 0.76$ & $3.27 \pm 0.12$ & $1.50 \pm 0.17^{\mathrm{b}}$ & $1.17 \pm 0.23^{\mathrm{c}}$ \\
P14-A2 & 14P & $5.63 \pm 0.15$ & $9.67 \pm 0.42^{\mathrm{a}}$ & $2.57 \pm 0.57$ & $4.03 \pm 0.55$ & $1.20 \pm 0.35^{\mathrm{b}}$ & $1.37 \pm 0.21^{\mathrm{c}}$ \\
Hb-A18 & Hb & $7.23 \pm 0.55$ & $15.63 \pm 1.65^{\mathrm{a}}$ & ND & ND & ND & ND \\
H1-17 & HA & $24.25 \pm 1.06$ & $1.03 \pm 0.06^{\mathrm{a}}$ & $1.07 \pm 0.12$ & $1.03 \pm 0.15$ & $1.30 \pm 0.10$ & $1.00 \pm 0.17^{\mathrm{c}}$ \\
\hline
\end{tabular}

The reactivity of each McAb against the listed detection antigens was evaluated by indirect ELISA with an antigen-coated plate. Results are expressed as the ratio of the optical density at $450 \mathrm{~nm}$ of the analyte McAb over that of the Sp20 negative control $(\mathrm{McAb} / \mathrm{Sp} 20 \mathrm{or} \mathrm{P} / \mathrm{N})$. $\mathrm{P} / \mathrm{N} \geq 2.1$ was the cutoff value for a reaction to be considered as positive. ${ }^{\mathrm{a}} \mathrm{P}<0.05, \mathrm{HA}$ and $\mathrm{P} 11-\mathrm{A} 2$ antibodies antigens vs. Heme group; ${ }^{b} \mathrm{P}<0.05$, peptide P11 vs. peptide P11F group; ${ }^{\mathrm{P}} \mathrm{P}<0.05$, peptide P14 vs. peptide P14F group. P11F, imidazole-rich P11 epitope from HA (FGIHH) with substitution of one imidazole-containing amino acid (tryptophan) with phenylalanine. P14R, imidazole-rich P14 epitope from HA (WYGYRH) with substitution of the first histidine with arginine; HA, hemagglutinin; Hb, hemoglobin; ND, not determined; McAb, monoclonal antibody; $\mathrm{P}$, positive; $\mathrm{N}$, negative.
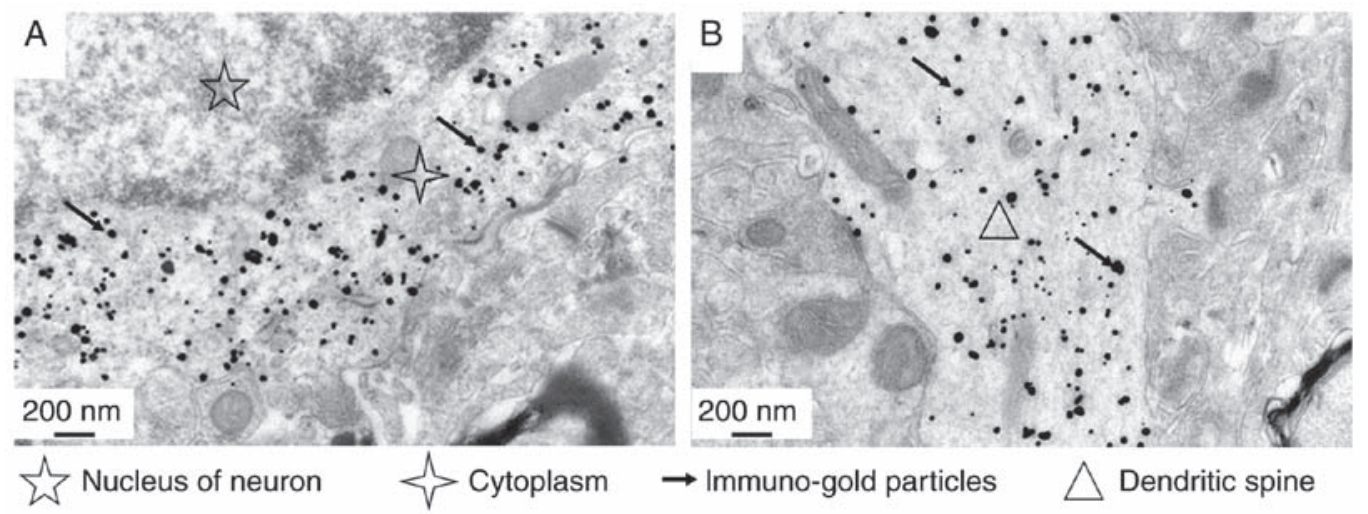

Figure 3. Immune colloidal gold electron microscopic analysis of the cross-reactive anti-hemagglutinin monoclonal antibody A1-10 on normal rat brain tissue. (A) Normal brain neuronal cells and (B) normal dendrites (scale bars, $200 \mathrm{~nm}$ ).

the ELISA plate. However, neither the modified polypeptide P11F nor P14R were able to block any of the McAbs. The HA-specific McAbs A1-16 and H1-17 were included as the negative control and system control. This result confirmed that all 3 cross-reactive McAbs react with either of the two epitopes, which also indicated that the 2 cross-reactive HA epitopes P11 and P14 are cross-reactive with each other; all 3 cross-reactive McAbs reacted with protoporphyrin, heme, P11 and P14, not only on the nitrocellulose membrane, but also in solution.

\section{Discussion}

HA is an important glycoprotein of IAV and a major antigenic component of the IAV vaccine that stimulates the body to produce protective antibodies. IAV vaccination may produce side effects or even lead to death. Identification of impurities in the vaccine has been performed to assess the cause of these serious side effects (10); however, few efforts were made to investigate the antigen itself. In the present study, 67 McAbs were prepared with the 2009 H1N1 HA as the antigen; among these, H1-13, H1-15 and A1-10 exhibited broad cross-activities. Antibodies against these HA epitopes react with imidazol ring-containing molecules, including His-tag and the porphyrin derivatives $\mathrm{Hb}$, protoporphyrin, chlorophyll and vitamin B12. In addition, the porphyrin ring is the basic structure for $\mathrm{Hg}$ in erythrocytes, myoglobin in muscle cells and the cytochrome $c$ respiratory chain in the mitochondrial membrane; thus, the present study speculated and confirmed that these cross-reactive antibodies may react with various cells in the body, including heme-rich red blood cells, myoglobin-rich muscle cells and metabolically active tissues including bone marrow, the liver and certain glandular tissues. In addition, the McAb A1-10 was demonstrated to react with brain cell cytoplasm and dendrites.

The HA protein shares a similar structure with imidazol ring-rich molecules, including His-tag, which reacted with all 3 cross-reactive McAbs. The antibody binds to the porphyrin ring-like structure, and the $\mathrm{N}$ atom in the imidazolyl group of histidine and the indolyl group of tryptophan form a coordination bond through binding with a transition metal ion to form a porphyrin ring-like structure; thus, it was assumed that a cross-reactive epitope on HA should contain a high abundance of histidine or tryptophan. By analyzing the amino 
A<smiles>NC(Cc1cnc[nH]1)C(=O)O</smiles>

Histidine<smiles>c1c[nH]cn1</smiles>

Imidizole<smiles>C1=C/C(=C/C2=CC=C/C2=C\C2=N/C(=C\c3ccc[nH]3)C=C2)N=C1</smiles>

Protoporphyrin<smiles></smiles>

Heme

B 1 MKAILVVLLYTFATANADTLCIGYHANNSTDTVDTVLEKNVTVTHSVNLLEDKHNGKLCK

61 LRGVAPLHLGKCNIAGWILGNPECESLSTASSWSYIVETPSSDNGTCYPGDFIDYEELRE 121 QLSSVSSFERFEIFPKTSSWPNHDSNKGVTAACPHAGAKSFYKNLIWLVKKGNSYPKLSK

181 SYINDKGKEVLVLWGIHHPSTSADQQSLYQNADAYVFVGSSRYSKKFKPEIAIRPKVRDR 241 EGRMNYYWTLVEPGDKITFEATGNLVVPRYAFAMERNAGSGIIISDTPVHDCNTTCQTPK 301 GAINTSLPFQNIHPITIGKCPKYVKSTKLRLATGLRNIPSIQSRGLFGAIAGFIEGGWTG 361 MVDGWYGYHHQNEQGSGYAADLKSTQNAIDEITNKVNSVIEKMNTQFTAVGKEFNHLEKR 421 IENLNKKVDDGFLDIWTYNAELLVLLENERTLDYHDSNVKNLYEKVRSQLKNNAKEIGNG 481 CFEFYHKCDNTCMESVKNGTYDYPKYSEEAKLNREEIDGVKLESTRIYQILAIYSTVASS 541 LVLVVSLGAISFWMCSNGSLQCRICI-

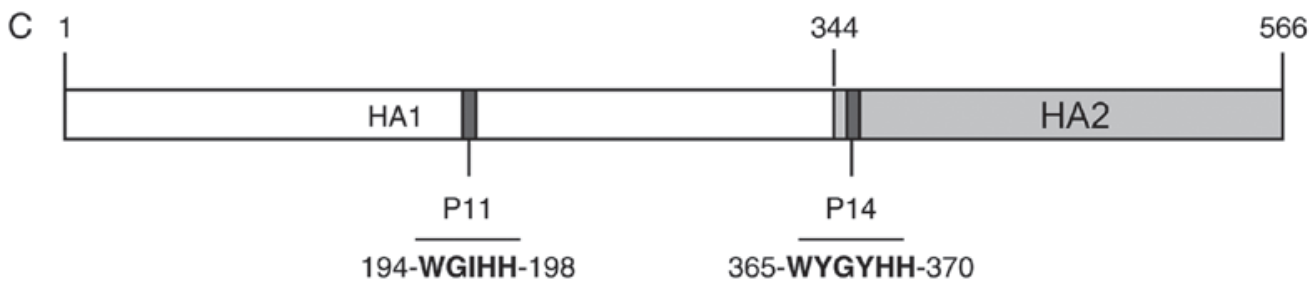

Figure 4. Chemical structures of the imidazole-containing molecules and the cross-reactive epitopes on HA. (A) Chemical structures of the imidazole-containing molecules; (B) HAs include HA1 (black) and HA2 (grey); the spinal peptide and fusion peptide are in bold, and the cross-reactive epitopes P11 and P14 are underlined and bold. (C) The relative positions of the cross-reactive epitopes P11 and P14 on HA. HA, hemagglutinin.

acid sequence of the 2009 H1N1 HA protein, the amino acid sequences 194-WGIHH-198 and 365-WYGYHH-370 were identified to have the characteristics required to form a porphyrin ring-like structure. The present results indicated that substitution of one of these amino acids abrogated the cross-reactivity of the McAbs, probably by disrupting the porphyrin ring-like structure. These 2 cross-reactive epitopes have been recognized as novel HA epitopes (36).

In addition, the antibodies of the HA cross-reactive epitopes induced were identified to have similar reactivity to those of cross-reactive antibodies generated through HA immunization; more interestingly, these antibodies have a higher reactivity with HA and heme than with the epitopes themselves, as HA and heme have more antigenic determinants.

Since the identification of broadly cross-reactive epitopes on HA, their clinical importance has been studied, including their roles in influenza symptoms and side effects of IAV vaccines. Only few studies on the anti-HA antibody-associated pathological effects of the antibody-dependent enhancement of infection, and its possible role in the pathogenesis of influenza have been reported (37); however, other speculations have been made regarding the associations between antibody and flu pathology. Lung samples of 75 young and middle-aged patients from the 2009 IAV pandemic demonstrated abnormally elevated C4d levels. C4d usually binds with an immune

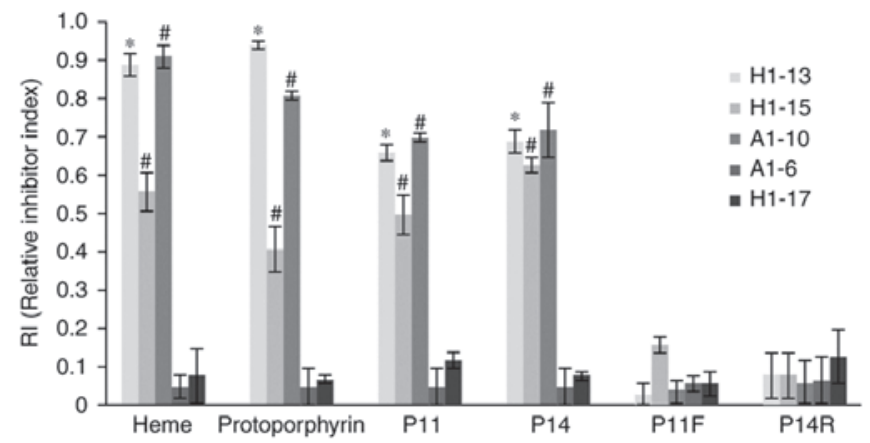

Figure 5. Cross-reactivity inhibitory assay of the anti-HA McAbs. The antigens (including heme, protoporphyrin, and P11, P14, P11F and P14R polypeptides; displayed on the $\mathrm{X}$-axis) were pre-reacted with individual $\mathrm{McAb}$ prior to addition to the HA-coated microtiter plate. The $\mathrm{y}$-axis displays the $\mathrm{RI}$ value calculated as $\mathrm{RI}=\left(\mathrm{OD}_{450}\right.$ of $\mathrm{McAb}-\mathrm{OD}_{450} \mathrm{McAb}$ pre-reacted with antigen)/ $/ \mathrm{OD}_{450}$ of $\mathrm{McAb}$. $\mathrm{RI} \leq 0.4$ indicates that the antibody does not react with the blocking antigen; RI 0.4-0.8 indicates that the antibody is reactive with the blocking antigen; $\mathrm{RI} \geq 0.8$ indicates that the antibody consistently reacted with the blocking antigen. "P<0.05, RI of H1-13 antibody in each group compared with that of A1-6 antibody (all are IgG subtypes). ${ }^{\text {" }} \mathrm{P}<0.05$, RI of A1-10 and H1-15 antibody in each group are compared with that of H1-17 antibody (all are IgM subtypes). P11F, imidazole-rich P11 epitope from $\mathrm{HA}(\mathrm{FGIHH})$ with substitution of one imidazole-containing amino acid (tryptophan) with phenylalanine; P14R, imidazole-rich P14 epitope from HA (WYGYRH) with substitution of the first histidine with arginine; RI, relative inhibitor index; Ig, immunoglobulin; McAbs, monoclonal antibodies; $\mathrm{HA}$, hemagglutinin; $\mathrm{OD}_{450}$, optical density at $450 \mathrm{~nm}$. 
complex; this suggested that severe influenza may result from pathological damage caused by immune complexes (38).

Cross-reactivity of HA-induced antibodies with heme may result in serious problems, as hemeproteins have diverse biological functions, including oxygen transport $(\mathrm{Hg}$, myoglobin, neuroglobin, cytoglobin, legHg), catalysis (cytochrome P450s, cytochrome $c$ oxidase, ligninases, peroxidases), electron transfer/transport (cytochrome $a-c$ ), sensory disambiguation (oxygen sensor FixL, soluble guanylyl cyclase, $\mathrm{CO}$ sensor CooA) and defense (catalase). The HA cross-reactive epitope-induced antibodies strongly bind with numerous important tissue types and organs; thus, HA-associated autoimmunopathology should be addressed.

Any hemeprotein malfunction may cause specific diseases. In addition, HA cross-reactive epitope-induced antibodies, which bind with hemoproteins, may induce malfunction. For instance, studies regarding $\mathrm{Hb}$ release in IAV infection are lacking; however, this is likely to occur, as HA interacts with erythrocytes, and the release of $\mathrm{Hb}$ occurs in certain infectious and autoimmune diseases (39). $\mathrm{Hb}$ also occurs outside of red blood cells and their progenitor lines. Other cell types that contain $\mathrm{Hb}$ include mesangial cells in the kidney, macrophages, alveolar cells and the A9 dopaminergic neurons in the substantia nigra. In these tissues, $\mathrm{Hg}$ has a non-oxygen-carrying function as a regulator of iron metabolism and an antioxidant (40). The autoantibody to human $\mathrm{Hb}$ was identified in the sera of patients with malaria, leishmania and systemic lupus erythematosus. Serum $\mathrm{Hb}$ antibody levels in lupus-prone mice also exhibited an age-dependent increase, with progressive organ sequestration. A suggestive link between anti-Hb and anti-Smith antibody responses was also observed (39). Myoglobin was identified in vertebrate muscle cells, including myocardial cells. Myocarditis is a common and severe complication of influenza (41); however, the underlying mechanism have remained elusive.

In conclusion, the present study identified 2 broad cross-reactive epitopes on HA, P11 (194-WGIHH-198) and P14 (365-WYGYHH-370), and demonstrated that antibodies against these epitopes react with $\mathrm{Hb}$ and numerous important normal tissue/organ types. Further study into whether such antibodies are involved in reducing anti-IAV immunity $(42,43)$ and immunopathological damage, as well as whether cross-reactive epitopes are associated with severe symptoms of influenza infection and serious adverse reactions to influenza vaccination may provide critical insight for influenza research and management.

\section{Acknowledgements}

The authors would like to thank Dr Mingjie Zhang from the Laboratory of Molecular Virology of the Center for Biologics Evaluation and Research (Food and Drug Administration, Silver Spring, MD, USA) for his assistance with the design and editing of the manuscript. The present study was supported by the National Key Research and Development Program of China (grant no. 2016YFD0500701-5), the Key Research and Development Plan of Shaanxi Province (grant no. 2017SF-091), The Health and family planning commission research fund project of Shaanxi Province (grant no. 2016D035) and the Natural Science Foundation of China (grant no. 81202373).

\section{References}

1. Cox NJ and Subbarao K: Influenza. Lancet 354: 1277-1282, 1999.

2. Chen GL and Subbarao K: Live attenuated vaccines for pandemic influenza. Curr Top Microbiol Immunol 333: 109-132, 2009.

3. Thompson WW, Shay DK, Weintraub E, Brammer L, Cox N, Anderson LJ and Fukuda K: Mortality associated with influenza and respiratory syncytial virus in the United States. Jama 289: 179-186, 2003.

4. Johnson NP and Mueller J: Updating the accounts: Global mortality of the 1918-1920 'Spanish' influenza pandemic. Bull Hist Med 76: 105-115, 2002.

5. Tumpey TM, Basler CF, Aguilar PV, Zeng H, Solórzano A, Swayne DE, Cox NJ, Katz JM, Taubenberger JK, Palese P, et al: Characterization of the reconstructed 1918 Spanish influenza pandemic virus. Science 310: 77-80, 2005.

6. Santos-Preciado J, Franco-Paredes C, Hernandez-Flores I, Tellez I, Del Rio C and Tapia-Conyer R: What have we learned from the novel influenza A (H1N1) pandemic in 2009 for strengthening pandemic influenza preparedness? Arch Med Res 40: 673-676, 2009.

7. Wiley DC and Skehel JJ: The structure and function of the hemagglutinin membrane glycoprotein of influenza virus. Annu Rev Biochem 56: 365-394, 1987.

8. Drescher J and Aron R: Influence of the amino acid differences between the hemagglutinin HA1 domains of influenza virus H1N1 strains on their reaction with antibody. J Med Virol 57: 397-404, 1999.

9. Evans D, Cauchemez S and Hayden FG: 'Prepandemic' immunization for novel influenza viruses, 'swine flu' vaccine, Guillain-Barré syndrome, and the detection of rare severe adversee vents. J Infect Dis 200: 321-328, 2009.

10. Nachamkin I, Shadomy SV, Moran AP, Cox N, Fitzgerald C, Ung H, Corcoran AT, Iskander JK, Schonberger LB and Chen RT: Anti-ganglioside antibody induction by swine (A/NJ/1976/H1N1) and other influenza vaccines: Insights into vaccine-associated Guillain-Barré syndrome. J Infect Dis 198: 226-233, 2008.

11. Israeli E, Agmon-Levin N, Blank $\mathrm{M}$, Chapman $\mathrm{J}$ and Shoenfeld Y: Guillain-Barré syndrome-a classical autoimmune disease triggered by infection or vaccination. Clin Rev Allergy Immunol 42: 121-130, 2012.

12. Simpson BS and Rajabally YA: Sensori-motor Guillain-Barré syndrome with anti-GD1b antibodies following influenza A infection. Eur J Neurol 16: e81, 2009.

13. Nakamura N, Nokura K, Zettsu T, Koga H, Tachi M, Terada M, Katoh H, Itoh Y, Osawa H, Ozeki T and Yamamoto H: Neurologic complications associated with influenza vaccination: Two adult cases. Intern Med 42: 191-194, 2003.

14. Wang DJ, Boltz DA, McElhaney J, McCullers JA, Webby RJ and Webster RG: No evidence of a link between influenza vaccines and Guillain-Barre syndrome-associated antiganglioside antibodies. Influenza Other Respir Viruses 6: 159-166, 2012.

15. Lei T, Siu KL, Kok KH, Chan KH, Chan EY, Hung IF, To KK, Li PC, Zhou J,Zheng BJ, et al: Anti-ganglioside antibodies were not detected in human subjects infected with or vaccinated against 2009 pandemic influenza A (H1N1) virus. Vaccine 30: 2605-2610, 2012.

16. Yuki N, Takahashi Y, Ihara T, Ito S, Nakajima T, Funakoshi K, Furukawa K, Kobayashi K and Odaka M: Lack of antibody response to Guillain-Barré syndrome-related gangliosides in mice and men after novel flu vaccination. J Neurol Neurosurg Psychiatry 83: 116-117, 2012.

17. Sencer DJ and Millar JD: Reflections on the 1976 swine flu vaccination program. Emerg Infect Dis 12: 29-33, 2006.

18. Souayah N, Nasar A, Suri MF and Qureshi AI: Guillain-Barre syndrome after vaccination in United States a report from the CDC/FDA vaccine adverse event reporting system. Vaccine 25 : 5253-5255, 2007

19. Manicassamy B, Medina RA, Hai R, Tsibane T, Stertz S, Nistal-Villán E, Palese P, Basler CF and García-Sastre A: Protection of mice against lethal challenge with 2009 H1N1 influenza A virus by 1918-like and classical swine H1N1 based vaccines. PLoS Pathog 6: e1000745, 2010.

20. Hanson BJ, Boon AC, Lim AP, Webb A, Ooi EE and Webby RJ: Passive immunoprophylaxis and therapy with humanized monoclonal antibody specific for influenza A H5 hemagglutinin in mice. Respir Res 7: 126, 2006.

21. Lipatov AS, Gitelman AK and Smirnov YuA: Prevention and treatment of lethal influenza A virus bronchopneumonia in mice by monoclonal antibody against haemagglutinin stem region. Acta Virol 41: 337-340, 1997. 
22. Stephenson I, Bugarini R, Nicholson KG, Podda A, Wood JM, Zambon MC and Katz JM: Cross-reactivity to highly pathogenic avian influenza $\mathrm{H} 5 \mathrm{~N} 1$ viruses after vaccination with nonadjuvanted and MF59-adjuvanted influenza A/Duck/Singapore/97 (H5N3) vaccine: A potential priming strategy. J Infect Dis 191: $1210-1215,2005$.

23. Hancock K, Veguilla V, Lu X, Zhong W, Butler EN, Sun H, Liu F, Dong L, DeVos JR, Gargiullo PM, et al: Cross-reactive antibody responses to the 2009 pandemic H1N1 influenza virus. N Engl J Med 361: 1945-1952, 2009.

24. Krause JC, Tsibane T, Tumpey TM, Huffman CJ, Basler CF and Crowe JE Jr: A broadly neutralizing human monoclonal antibody that recognizes a conserved, novel epitope on the globular head of the influenza H1N1 virus hemagglutinin. J Virol 85: 10905-10908, 2011.

25. Simmons CP, Bernasconi NL, Suguitan AL, Mills K, Ward JM, Chau NV, Hien TT, Sallusto F, Ha do Q, Farrar J, et al: Prophylactic and therapeutic efficacy of human monoclonal antibodies against H5N1 influenza. PLoS Med 4: e178, 2007.

26. Tan GS, Krammer F, Eggink D, Kongchanagul A, Moran TM and Palese P: A pan-H1 anti-hemagglutinin monoclonal antibody with potent broad-spectrum efficacy in vivo. J Virol 86: 6179-6188, 2012

27. Alam S and Sant AJ: Infection with seasonal influenza virus elicits CD4 T cells specific for genetically conserved epitopes that can be rapidly mobilized for protective immunity to pandemic H1N1 influenza virus. J Virol 85: 13310-13321, 2011.

28. Clute SC, Watkin LB, Cornberg M, Naumov YN, Sullivan JL, Luzuriaga K, Welsh RM and Selin LK: Cross-reactive influenza virus-specific $\mathrm{CD}^{+} \mathrm{T}$ cells contribute to lymphoproliferation in Epstein-Barr virus-associated infectious mononucleosis. J Clin Invest 115: 3602-3612, 2005.

29. Weinfurter JT, Brunner K, Capuano SV III, Li C, Broman KW, Kawaoka Y and Friedrich TC: Cross-reactive T cells are involved in rapid clearance of 2009 pandemic H1N1 influenza virus in nonhuman primates. PLoS Pathog 7: e1002381, 2011.

30. Yu CI, Gallegos M, Marches F, Zurawski G, Ramilo O, Garcia-Sastre A, Banchereau J and Palucka AK: Broad influenza-specific $\mathrm{CD} 8^{+} \mathrm{T}$-cell responses in humanized mice vaccinated with influenza virus vaccines. Blood 112: 3671-3678, 2008.

31. Guo C, Xie X, Li H, Zhao P, Zhao X, Sun J, Wang H, Liu Y, $\mathrm{Li} \mathrm{Y,} \mathrm{Hu} \mathrm{Q,} \mathrm{Hu} \mathrm{J} \mathrm{and} \mathrm{Li} \mathrm{Y:} \mathrm{Prediction} \mathrm{of} \mathrm{common} \mathrm{epitopes} \mathrm{on}$ hemagglutinin of the influenza A virus (H1 subtype). Exp Mol Pathol 98: 79-84, 2015.
32. Guo CY, Li HJ, Liu Y, Zhao XR, Wang X, Feng Q, Li Y and Hu J: Preparation and partial characterization of monoclonal antibodies against HA protein of $\mathrm{H} 1$ subtype influenza virus. Xi Bao Yu Fen Zi Mian Yi Xue Za Zhi 28: 177-180, 2012 (In Chinese).

33. Zhang MJ, Wang MX, Jiang SZ, Xiu ZZ and Ma WY: Preparation and characterization of the monoclonal antibodies against Japanese encephalitis virus. Acta Virol 36: 533-540, 1992.

34. Thomson TA, Zhou C, Chu C and Knight B: Tissue microarray for routine analysis of breast biomarkers in the clinical laboratory. Am J Clin Pathol 132: 899-905, 2009.

35. Yi H, Leunissen J, Shi G, Gutekunst C and Hersch S: A novel procedure for pre-embedding double immunogold-silver labeling at the ultrastructural level. J Histochem Cytochem 49: 279-284, 2001.

36. Hu W: Highly conserved domains in hemagglutinin of influenza viruses characterizing dual receptor binding. Natural Science 2: 1005-1014, 2010.

37. Dutry I, YenHl,LeeH,Peiris MandJaume M: Antibody-dependent enhancement (ADE) of infection and its possible role in the pathogenesis of influenza. BMC Proc 5 (Suppl 1): S62, 2011.

38. Monsalvo AC, Batalle JP, Lopez MF, Krause JC, Klemenc J, Hernandez JZ, Maskin B, Bugna J, Rubinstein C, Aguilar L, et al: Severe pandemic 2009 H1N1 influenza disease due to pathogenic immune complexes. Nat Med 17: 195-199, 2011.

39. Bhatnagar H, Kala S, Sharma L, Jain S, Kim KS and Pal R: Serum and organ-associated anti-hemoglobin humoral autoreactivity: Association with anti-Sm responses and inflammation. Eur J Immunol 41: 537-548, 2011.

40. Biagioli M, Pinto M, Cesselli D, Zaninello M, Lazarevic D, Roncaglia P, Simone R, Vlachouli C, Plessy C, Bertin N, et al: Unexpected expression of alpha- and beta-globin in mesencephalic dopaminergic neurons and glial cells. Proc Natl Acad Sci USA 106: 15454-15459, 2009.

41. Ukimura A, Satomi H, Ooi Y and Kanzaki Y: Myocarditis associated with influenza A H1N1pdm2009. Influenza Res Treat 2012: 351979, 2012.

42. Chen AT, Cornberg M, Gras S, Guillonneau C, Rossjohn J, Trees A, Emonet S, de la Torre JC, Welsh RM and Selin LK: Loss of anti-viral immunity by infection with a virus encoding a cross-reactive pathogenic epitope. PLoS Pathog 8: e1002633, 2012.

43. Marazzi I, Ho JS, Kim J, Manicassamy B, Dewell S, Albrecht RA, Seibert CW, Schaefer U, Jeffrey KL, Prinjha RK, et al: Suppression of the antiviral response by an influenza histone mimic. Nature 483: 428-433, 2012. 